\title{
Exigência de Triptofano para Frangos de Corte de 1 A 21 Dias de Idade ${ }^{1}$
}

\section{Altivo José de Castro², Paulo Cezar Gomes ${ }^{3}$, Júlio Maria Ribeiro Pupa 4 , Horacio Santiago Rostagno ${ }^{3}$, Luiz Fernando Teixeira Albino ${ }^{3}$, Adriana Helena Nascimento ${ }^{4}$}

\begin{abstract}
RESUMO - Com o objetivo de determinar as exigências nutricionais em triptofano para frangos de corte machos e fêmeas, durante a fase inicial, foram utilizados 800 pintos machos e fêmeas, no período de 1 a 21 dias de idade, com peso médio inicial de 44,7 e 44,6 g, respectivamente. As aves receberam uma dieta basal deficiente em triptofano $(0,180 \%)$. O delineamento experimental utilizado foi em blocos casualizados em arranjo fatorial 5 x 2 (tratamento x sexo), com quatro repetições por sexo e 20 aves/unidade experimental. Os tratamentos consistiram da suplementação da dieta basal com cinco níveis de triptofano ( $(0 ; 0,015 ; 0,030 ; 0,045 ;$ e $0,060 \%)$. Foi avaliado o desempenho das aves, sendo os valores de exigências em triptofano estimados por meio dos modelos de regressão polinomial e LRP. Foi considerado o coeficiente de digestibilidade verdadeira do triptofano da dieta basal de 90,33\%. As suplementações com L-triptofano influenciaram o ganho de peso dos machos, porém, não houve efeito sobre a conversão alimentar, sugerindo recomendação mínima de 0,212 e 0,195\% de triptofano total e digestível, respectivamente. Entretanto, para as fêmeas, as suplementações com L-triptofano influenciaram o ganho de peso e a conversão alimentar, sugerindo recomendação mínima de 0,208 e 0,191\% de triptofano total e digestível, respectivamente.
\end{abstract}

Palavras-chave: aminoácido, exigência, frango de corte, triptofano

\section{Tryptophan Requirement for Broilers from 1 to 21 Days of Age}

\begin{abstract}
With the objective to determine the tryptophan nutritional requirements for male and female broilers, during the initial phase, 800 male and female chicks, from 1 to 21 days of age, with average initial weight of 44.7 and $44.6 \mathrm{~g}$, respectively, were used. The birds received a deficient tryptophan basal diet $(.180 \%)$. A completely randomized blocks experimental design, in a $5 \mathrm{x} 2$ factorial arrangement (treatment $x$ sex), with four replicates per sex and 20 chicks per experimental unit, was used. The treatments consisted on a basal diet supplemented with five tryptophan levels $(0, .015, .030, .045$, and $.060 \%)$. Chick's performance was evaluated, and the tryptophan requirement values were estimated by means of the polynomial regression models and LRP. The tryptophan true digestibility coefficient of the basal diet was $90.33 \%$. The supplementations with L-tryptophan influenced the males weight gain, however, there was no effect on the feed: gain, suggesting a minimum recommendation of .212 and $.195 \%$ for total tryptophan and digestible, respectively. However, for the females, the supplementations with L- tryptophan influenced the weight gain and the feed: gain, suggesting a minimum recommendation of .208 and $.191 \%$ for total and digestible tryptophan, respectively.
\end{abstract}

Key Words: amino acid, broiler, requirement, tryptophan

\section{Introdução}

Os aminoácidos exercem importantes funções como componente das proteínas, são essenciais para mantença e produção e apresentam papel essencial em vários processos metabólicos. O triptofano está envolvido na síntese de niacina e serotonina, sendo portanto, imprescindível que esteja em níveis adequados nas rações, para que haja crescimento rápido e eficiente das aves.

É de grande importância formular rações de forma econômica e que atenda às exigências nutricionais das aves. Segundo TEETER et al (1993), o padrão e a quantidade de aminoácidos consumidos pelas aves têm grande influência sobre ganho de peso, composição do ganho e consumo de alimento.

Para obter maior precisão na formulação e no balanceamento das rações e torná-las mais econômicas, é necessário conhecer a composição nutricional dos alimentos, bem como suas limitações. Porém, a maior parte dos aminoácidos ingeridos pelos animais está na forma de proteínas, que, ao serem digeridas, resultam em pequenos peptídeos e aminoácidos livres passíveis de serem absorvidos. É de fundamental importância conhecer a digestibilidade destes aminoácidos nos alimentos para que se possam formular dietas mais eficientes.

\footnotetext{
${ }^{1}$ Parte da tese de mestrado apresentada pelo primeiro autor à UFV.

2 Zootecnista, Mestre, Professor da PUC. E.mail: ajc@nutris.com.br

3 Professor do Departamento de Zootecnia, UFV - 36571-000 - Viçosa-MG. Bolsista CNPq

4 Doutor em Zootecnia - UFV - 36571-000 - Viçosa-MG. E.mail: pupa@tdnet.com.br

5 Doutor em Zootecnia - UFV - AGROCERES - Rio Claro, SP.
} 
As exigências de triptofano para frangos de corte no período de 1 a 21 dias de idade, segundo as recomendações do AEC (1987) e ROSTAGNO et al (1992), é $0,070 \%$ de Trp/Mcal de energia metabolizável. Já o NRC (1994) recomenda 0,20\% em rações com $3.200 \mathrm{kcal} / \mathrm{kg}$ de energia metabolizável.

O objetivo do presente trabalho foi estabelecer as exigências nutricionais de triptofano para frangos de corte machos e fêmeas, durante a fase inicial (1 a 21 dias de idade).

\section{Material e Métodos}

O presente experimento foi conduzido nas dependências da Seção de Avicultura do Departamento de Zootecnia, do Centro de Ciências Agrárias da Universidade Federal de Viçosa, no período de 25 de abril a 16 de maio de 1996.

Foram utilizados 800 frangos de corte machos e fêmeas (HUBBARD), no período de 1 a 21 dias de idade, com peso inicial médio de 44,7 g., para ambos os sexos.
Os frangos foram distribuídos ao acaso em 40 boxes de 1,50 x 1,50 m, com piso de cimento, cobertos com cepilho de madeira. Foram utilizados dois galpões de alvenaria, com dimensões de 4,50 x 19,40 m e 2,80 m de pé-direito, cobertos com telhas de cimento-amianto, lanternim, laterais com muretas de $0,50 \mathrm{~m}$ de altura e o restante fechado com tela de $1 / 2^{2}$ à prova de pássaros e cortinas plásticas levantadas verticalmente no sentido de baixo para cima.

O programa de luz contínuo, 24 horas de luz (natural + artificial), foi adotado durante todo o período experimental usando lâmpadas de $60 \mathrm{~W}$. Foram utilizadas lâmpadas de infravermelho de $250 \mathrm{~W} /$ box, com altura regulável para o aquecimento dos pintos até $\mathrm{o}$ 14 o dia de idade.

A temperatura e a umidade relativa do ar observadas no interior dos galpões foram, para o galpão 1 , máxima média de $30,4^{\circ} \mathrm{C}$ e mínima média de $17,5^{\circ} \mathrm{C}$ e, para o galpão 2 , máxima média de $30,8^{\circ} \mathrm{C}$ e mínima média de $17,4{ }^{\circ} \mathrm{C}$. A umidade relativa média do ar para ambos os galpões foi de $78,5 \%$.

Tabela 1 - Composição química dos alimentos, expressos na base da matéria natural Table 1 - Chemical composition of the feedstuffs, in as fed basis

\begin{tabular}{|c|c|c|c|c|c|}
\hline $\begin{array}{l}\text { Nutrientes } \\
\text { Nutrients }\end{array}$ & $\begin{array}{l}\text { Farinha de } \\
\text { carne e ossos } \\
\text { Meat and } \\
\text { bone meal } \\
\end{array}$ & $\begin{array}{l}\text { Farelo de } \\
\text { soja } \\
\text { Soybean } \\
\text { meal } \\
\end{array}$ & $\begin{array}{c}\text { Farelo de } \\
\text { trigo } \\
\text { Wheat } \\
\text { bran } \\
\end{array}$ & $\begin{array}{l}\text { Glúten de } \\
\text { milho } \\
\text { Corn gluten } \\
\text { meal } \\
\end{array}$ & $\begin{array}{c}\text { Milho } \\
\text { Corn }\end{array}$ \\
\hline $\begin{array}{l}\mathrm{PB}^{1}(\%) \\
C P\end{array}$ & 40,600 & 44,500 & 15,920 & 58,380 & 8,190 \\
\hline $\begin{array}{l}\mathrm{EM}^{2}(\mathrm{Mcal} / \mathrm{kg}) \\
M E\end{array}$ & 1,705 & 2,283 & 1,526 & 3,624 & 3,416 \\
\hline $\begin{array}{l}\mathrm{FB}^{3}(\%) \\
C F\end{array}$ & 1,500 & 6,500 & 9,550 & 1,180 & 1,780 \\
\hline $\begin{array}{l}\mathrm{Ca}^{1}(\%) \\
\mathrm{P} \text { total }^{1}(\%)\end{array}$ & $\begin{array}{r}12,500 \\
6,690\end{array}$ & $\begin{array}{l}0,330 \\
0,660\end{array}$ & $\begin{array}{l}0,120 \\
0,780\end{array}$ & $\begin{array}{l}0,040 \\
0,480\end{array}$ & $\begin{array}{l}0,030 \\
0,270\end{array}$ \\
\hline $\begin{array}{l}\text { Total P } \\
\text { P disponível }^{4}(\%)\end{array}$ & 6,690 & 0,220 & 0,260 & 0,160 & 0,090 \\
\hline $\begin{array}{l}\text { Available P } \\
\mathrm{Na}^{3}(\%) \\
\text { Triptofano }^{2}(\%)\end{array}$ & $\begin{array}{l}0,440 \\
0,220\end{array}$ & $\begin{array}{l}0,091 \\
0,720\end{array}$ & $\begin{array}{l}0,042 \\
0,230\end{array}$ & $\begin{array}{l}0,025 \\
0,290\end{array}$ & $\begin{array}{l}0,021 \\
0,070\end{array}$ \\
\hline $\begin{array}{l}\text { Tryptophan } \\
\text { Lisina }^{2}(\%)\end{array}$ & 1,900 & 2,830 & 0,660 & 0,840 & 0,200 \\
\hline $\begin{array}{l}\text { Lysine } \\
\text { Metionina }^{2}(\%) \\
\text { Methionine }\end{array}$ & 0,610 & 0,560 & 0,230 & 1,230 & 0,170 \\
\hline $\begin{array}{l}\text { Met+Cis }{ }^{2}(\%) \\
\text { Meth+Cys }\end{array}$ & 0,750 & 1,340 & 0,520 & 2,700 & 0,350 \\
\hline $\begin{array}{l}1 \text { Análises realizadas } \\
2 \text { Análises realizadas } \\
3 \text { Valores obtidos por } \\
4 \text { Valores calculados. } \\
1 \text { Analyses were done at } \\
2 \text { Analyses were done a } \\
3 \text { Values obtained by RO } \\
4 \text { Calculated values. }\end{array}$ & $\begin{array}{l}\text { ratório de Nutrição } \\
\text { ratório Central - M } \\
\text { GNO et al. (1992). } \\
\text { utrition Lab, Departan } \\
\text { Foods S/A Central L } \\
\text { et al. (1992). }\end{array}$ & $\begin{array}{l}\text { aal do Depa } \\
\text { a Alimentos } \\
\text { Animal Scien }\end{array}$ & de Zoote & & \\
\hline
\end{tabular}


Rev. bras. zootec.

A composição dos ingredientes das rações experimentais encontra-se na Tabela 1.

Foi utilizada uma ração basal deficiente em triptofano, formulada à base de milho, farelo de soja, farinha de carne e ossos, farelo de trigo e glúten de milho (Tabela 2). O delineamento experimental utilizado foi em blocos casualizados (bloco = galpão), com cinco tratamentos, dois sexos, quatro repetições por sexo e vinte aves por unidade experimental. Os tratamentos foram constituídos dos níveis de 0,000 ; 0,$015 ; 0,030 ; 0,045 ;$ e $0,060 \%$ de suplementação com L-triptofano $(98,5 \%)$ à ração basal, correspondendo aos níveis de 0,$180 ; 0,195 ; 0,210 ; 0,225 ;$ e $0,240 \%$ de triptofano nas rações experimentais. As rações e a água foram fornecidas à vontade, em comedouros tubulares e bebedouros pendulares, respectivamente, conforme manejo convencional.

As exigências nutricionais mínimas, exceto de triptofano, foram atendidas segundo as recomendações de ROSTAGNO et al (1992), enquanto as suplementações com L-triptofano foram feitas em substituição ao caulim, usado como inerte nas rações experimentais.

As aves foram pesadas no $1^{\circ}$ e e $21^{\circ}$ dia de idade, para avaliação de ganho de peso, consumo de ração e conversão alimentar.

Para determinar a exigência de triptofano digestível, foi considerado o coeficiente de digestibilidade verdadeira do triptofano no milho, no farelo de trigo, no glúten de milho, no farelo de soja, e na farinha de carne e ossos, de 89,5; 78,3; 97,0; 90,9 e $80,6 \%$, respectivamente, de acordo com ALBINO et al (1992), AEC (1993) e PUPA (1995). A partir destes dados, foi calculado o coeficiente de digestibilidade verdadeira do triptofano da ração basal. O cálculo foi efetuado aplicando-se o coeficiente de digestibilidade verdadeira do triptofano de cada ingrediente da ração, em função de sua quantidade utilizada. A soma dos valores obtidos para cada ingrediente determinou a quantidade de triptofano digestível presente na ração basal. A exigência estimada de triptofano total presente na ração representou $100 \%$ e o valor obtido de triptofano digestível resultou no coeficiente de digestibilidade verdadeira teórico da ração basal, que foi $90,33 \%$. O triptofano sintético adicionado na forma de L-triptofano foi considerado como $100 \%$ digestível.

As análises de variância foram realizadas de acordo com o seguinte modelo:

$$
Y_{i j k l}=\mu+B_{i}+S_{j}+N / S_{j k}+\varepsilon_{i j k l}
$$

em que $Y_{\mathrm{ijkl}}$ é produção observada na unidade expe-
Tabela 2 - Composição percentual da ração basal Table 2 - Percent composition of basal diets

\begin{tabular}{|c|c|}
\hline $\begin{array}{l}\text { Ingredientes } \\
\text { Ingredient }\end{array}$ & $\begin{array}{c}\text { Quantidade }(\mathrm{kg}) \\
\text { Amount }\end{array}$ \\
\hline Milho & 61,870 \\
\hline Corn & \\
\hline Farelo de soja & 10,000 \\
\hline Soybean meal & \\
\hline Farinha de carne e ossos & 4,900 \\
\hline Meat and bone meal & \\
\hline $\begin{array}{l}\text { Farelo de trigo } \\
\text { Wheat bran }\end{array}$ & 7,000 \\
\hline $\begin{array}{l}\text { Farelo glúten de milho } \\
\text { Corn gluten meal }\end{array}$ & 13,200 \\
\hline $\begin{array}{l}\text { Cálcario } \\
\text { Limestone }\end{array}$ & 0,900 \\
\hline $\begin{array}{l}\text { Fosfato bicálcico } \\
\text { Dicalcium phosphate }\end{array}$ & 0,100 \\
\hline $\begin{array}{l}\text { Óleo de soja } \\
\text { Soybean oil }\end{array}$ & 0,500 \\
\hline $\begin{array}{l}\text { Sal } \\
\text { Salt }\end{array}$ & 0,300 \\
\hline $\begin{array}{l}\text { Inerte } \\
\text { Inert }\end{array}$ & 0,060 \\
\hline $\begin{array}{l}\mathrm{L} \text {-lisina } \mathrm{HCl}(98,5 \%) \\
L \text { - lysine } \mathrm{HCL}\end{array}$ & 0,650 \\
\hline $\begin{array}{l}\text { DL-Metionina }(99 \%) \\
\text { DL-methionine }\end{array}$ & 0,100 \\
\hline $\begin{array}{l}\text { L-Treonina }(98 \%) \\
\text { L-Threonine }\end{array}$ & 0,050 \\
\hline $\begin{array}{l}\text { Premix } \\
\text { Premix }\end{array}$ & 0,370 \\
\hline
\end{tabular}

Premix

\begin{tabular}{|c|c|}
\hline & $\begin{array}{c}\text { Valores calculados } \\
\text { Calculated values }\end{array}$ \\
\hline Proteína bruta $(\%)$ & 21,02 \\
\hline \multicolumn{2}{|l|}{ Crude protein } \\
\hline Energia metabolizável (Mcalkg) & 3,086 \\
\hline \multicolumn{2}{|l|}{ Metabolizable energy } \\
\hline Cálcio (\%) & 1,033 \\
\hline \multicolumn{2}{|l|}{ Calcium } \\
\hline Fósforo disponível (\%) & 0,500 \\
\hline \multicolumn{2}{|l|}{ Available phosphorum } \\
\hline Triptofano $(\%)$ & 0,180 \\
\hline \multicolumn{2}{|l|}{ Tryptophan } \\
\hline Triptofano digestível verdadeiro (\%) & 0,163 \\
\hline \multicolumn{2}{|l|}{ True digestible tryptophan } \\
\hline $\operatorname{Lisina}(\%)$ & 1,166 \\
\hline \multicolumn{2}{|l|}{ Lysine } \\
\hline Metionina $(\%)$ & 0,468 \\
\hline \multicolumn{2}{|l|}{ Methionine } \\
\hline Metionina + cistina $(\%)$ & 0,879 \\
\hline \multicolumn{2}{|l|}{ Methionine + Cystine } \\
\hline Treonina $(\%)$ & 0,766 \\
\hline Threonine & \\
\hline \multicolumn{2}{|c|}{ 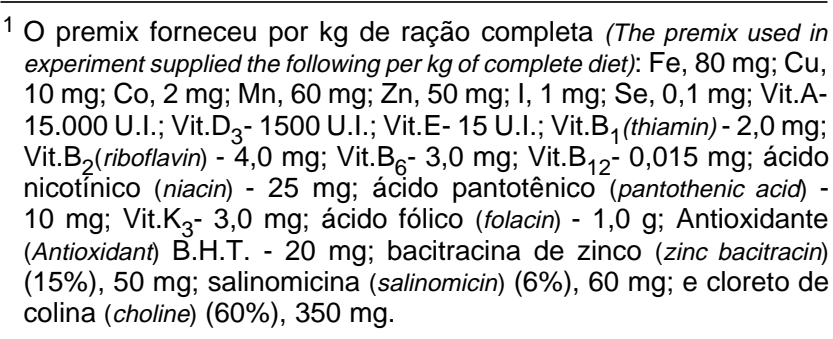 } \\
\hline
\end{tabular}


Tabela 3 - Efeito de diferentes níveis de triptofano (Trp) na dieta sobre o desempenho de frangos de corte machos (M) e fêmeas (F), de 1 a 21 dias de idade

Table 3 - Effect of different dietary tryptophan levels on the male and female broiler performance from 1 to 21 days of age

\begin{tabular}{|c|c|c|c|c|}
\hline $\begin{array}{l}\text { Nível de triptofano (\%) } \\
\text { Tryptophan level }\end{array}$ & $\begin{array}{l}\text { Sexo } \\
\text { Sex }\end{array}$ & $\begin{array}{c}\text { Ganho de peso }(\mathrm{g}) \\
\text { Weight gain }\end{array}$ & $\begin{array}{l}\text { Consumo de ração }(\mathrm{g}) \\
\text { Feed intake }\end{array}$ & $\begin{array}{l}\text { Conversão alimentar } \\
\text { Feed:gain ratio }\end{array}$ \\
\hline 0,180 & $\mathrm{M}$ & 665,8 & 1027,8 & 1,543 \\
\hline 0,195 & M & 695,5 & 1068,7 & 1,537 \\
\hline 0,210 & M & 722,9 & 1102,7 & 1,525 \\
\hline 0,225 & M & 684,9 & 1041,9 & 1,520 \\
\hline 0,240 & M & 683,6 & 1045,1 & 1,529 \\
\hline \multicolumn{5}{|l|}{ Média } \\
\hline Mean & & 690,5 & 1057,2 & 1,531 \\
\hline 0,180 & $\mathrm{~F}$ & 616,9 & 970,9 & 1,574 \\
\hline 0,195 & $\mathrm{~F}$ & 657,4 & 1016,2 & 1,545 \\
\hline 0,210 & $\mathrm{~F}$ & 640,0 & 991,3 & 1,548 \\
\hline 0,225 & $\mathrm{~F}$ & 635,8 & 987,3 & 1,552 \\
\hline 0,240 & $\mathrm{~F}$ & 630,1 & 997,3 & 1,583 \\
\hline \multicolumn{5}{|l|}{ Média } \\
\hline Mean & & 636,0 & 992,6 & 1,560 \\
\hline Triptofano (\%) & $\mathrm{M}$ & $* * *$ & $* *$ & $\mathrm{~ns}$ \\
\hline Tryiptophan & $\mathrm{F}$ & $*$ & $\mathrm{~ns}$ & $* *$ \\
\hline $\begin{array}{l}\text { Coeficiente de variação }(\%) \\
\text { Coefficient of variation }\end{array}$ & & 2,79 & 3,18 & 1,48 \\
\hline
\end{tabular}

rimental l, do nível de triptofano $\mathrm{k}$, do sexo je do bloco $\mathrm{i} ; \mu$, média geral; $\mathrm{B}_{\mathrm{i}}$, efeito do bloco i ( $\mathrm{i}=1$ e 2 ); $\mathrm{S}_{\mathrm{j}}$, efeito do sexo $\mathrm{j}(\mathrm{j}=1 \mathrm{e} 2) ; \mathrm{N} / \mathrm{S}_{\mathrm{jk}}$, efeito dos níveis de triptofano k dentro do sexo j; e $\varepsilon_{\mathrm{ijkl}}$, erro aleatório associado a cada observação.

As análises estatísticas dos parâmetros analisados foram realizadas de acordo com o programa SAEG (UNIVERSIDADE FEDERAL DE VIÇOSA - UFV, 1995). As estimativas das exigências de triptofano foram estabelecidas por meio dos modelos de regressão polinomial e descontínuo LRP - Linear Response Plateau (BRAGA, 1983), considerando-se, na escolha do modelo, uma vez respeitada a interpretação biológica, o valor da menor soma de quadrados dos desvios.

\section{Resultados e Discussão}

Os resultados de desempenho estão apresentados na Tabela 3. Houve efeito significativo dos níveis de triptofano sobre ganho de peso dos machos $(\mathrm{P} \leq 0,001)$ e das fêmeas $(\mathrm{P} \leq 0,05)$ e conversão alimentar das fêmeas $(\mathrm{P} \leq 0,01)$.

Verificou-se que a deficiência de triptofano foi prejudicial ao ganho de peso dos frangos de corte em ambos os sexos. Resultados semelhantes foram obtidos por WARNICK e ANDERSON (1968) e
ROGERS e PESTI (1990), utilizando frangos de corte, e POWELL e GEHLE (1977), que observaram redução no ganho de peso das frangas que receberam rações com deficiência em triptofano.

Verificou-se também que o excesso de triptofano nas dietas afetou o ganho de peso de forma negativa, o que está de acordo com KOELKEBECK et al. (1991), que observaram redução no ganho de peso das poedeiras em dietas contendo altos níveis de triptofano. Esses autores observaram, ainda, que o efeito do excesso de triptofano sobre a redução do ganho de peso foi mais evidente que o excesso de metionina.

Também houve efeito dos teores de triptofano sobre o consumo de ração dos machos $(\mathrm{P} \leq 0,01)$, o que está de acordo com ALSTER et al (1980) e ROGERS e PESTI (1990).

Pela diferença observada no ganho de peso dos machos em relação às fêmeas, torna-se viável trabalhar com sexos separados, uma vez que os machos apresentaram maior ganho de peso.

As exigências de triptofano para frangos de corte machos e fêmeas, de 1 a 21 dias de idade, encontram-se na Tabela 4 e nas Figuras 1, 2 e 3.

A exigência de triptofano total, ajustada por meio do modelo de regressão quadrática, com base nos resultados de ganho de peso dos machos, foi estimada 


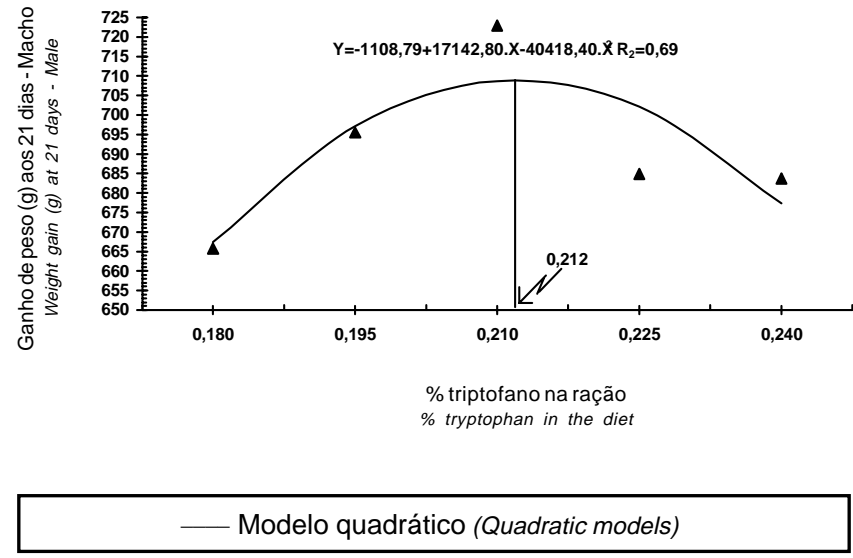

Figura 1 - Efeito dos níveis de triptofano sobre ganho de peso (g/ave) de frangos de corte machos, de $1 \mathrm{a}$ 21 dias de idade.

Figure 1 - Effect of the dietary tryptophan levels on weight gain ( $\mathrm{g} / \mathrm{bird}$ ) of broiler males, from 1 to 21 days of age.

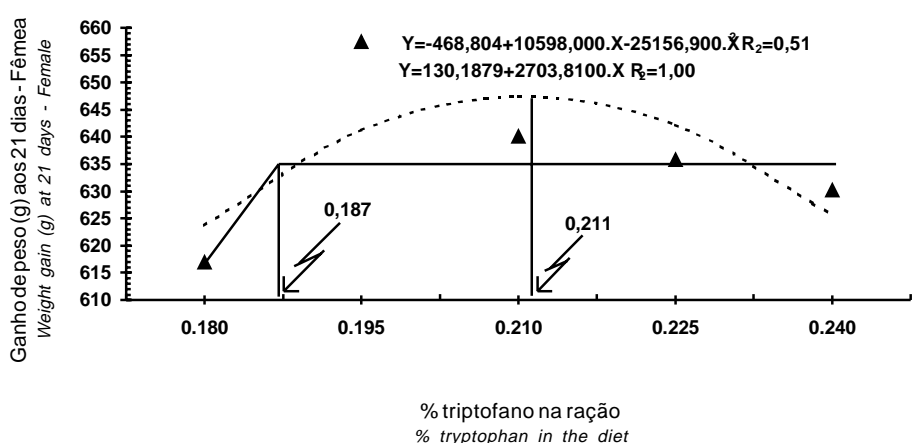

----- Modelo quadrático (Quadratic model) - Linear response plateau

Tabela 4 - Sumário das análises de determinação das exigências de triptofano, estimados por meio dos modelos de regressão

Table 4 - Summary of the analyses of determination of the trypthophan requirement, estimated by means of the regression models

\begin{tabular}{lcccc}
\hline $\begin{array}{l}\text { Modelo } \\
\text { Models }\end{array}$ & Equação de regressão & Pmáx/Pmín & Exigência & $\mathrm{R}^{2}$ \\
& Regression equation & Maximum or & $\mathrm{SQD}^{2}$ \\
& minimum point & Trp (\%) & $S S D$ & \\
\hline
\end{tabular}

Quadrático

Quadractic effect

Macho

Male

$\begin{array}{lllll}\text { Ganho de peso (g/ave) } \quad \hat{Y}=-1108,8+17142,8 X-40418,4 X 2 & 708,92 & 0,212 & 0,69 * * * & 540,66\end{array}$

Weight gain

Fêmea

female

Ganho de peso (g/ave)

Weight gain

Conversão alimentar $\quad \hat{\mathrm{Y}}=3,189-15,8373 \mathrm{X}+38,0968 \mathrm{X} 2$
$\hat{\mathrm{Y}}=-468,8+10598,0 \mathrm{X}-25156,9 \mathrm{X} 2$
647,37

0,211

$0,51 *$

424,98

Feed:gain ratio

\begin{tabular}{|c|c|c|c|c|c|}
\hline Modelo & Equação da reta & Platô3 & Exigência & $\mathrm{R}^{2}$ & $\mathrm{SQD}^{2}$ \\
\hline Model & Equation & $\begin{array}{c}\text { Breakpoint } \\
\operatorname{Trp}(\%)\end{array}$ & Requirement & & $S S D$ \\
\hline
\end{tabular}

\section{LRP}

Fêmea

Female

Ganho de peso (g/ave) $\quad \hat{\mathrm{Y}}=130,188+2703,8100 \mathrm{X}$

635,26

0,187

$1,00 *$

49,361

Weight gain

*** $(P \leq 0,001),{ }^{* *}(P \leq 0,01) e^{*}(P \leq 0,05)$ pelo teste $F$.

1 Pmáx (Ponto de máximo) e Pmín (Ponto de mínimo).

2 SQD - Soma de quadrados dos desvios (SSD - Square sum of deviation).

$\mathrm{R}^{2}$ Coeficiente de determinação (coefficient of determination). 


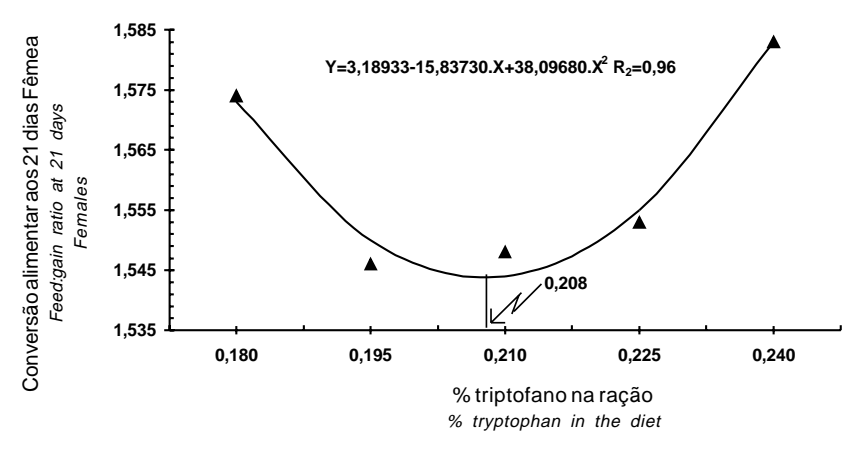

Modelo quadrático (Quadratic models)

Figura 3 - Efeito dos níveis de triptofano sobre conversão alimentar de frangos de corte fêmeas, de 1 a 21 dias de idade.

Figure 3 - Effect of the dietary tryptophan levels on ,feed: gain of broiler females, from 1 to 21 days of age.

em $0,212 \%$ (Tabela 4, Figura 1 ). As exigências de triptofano total, ajustadas por meio do modelo de regressão quadrática, para a conversão alimentar, e do modelo LRP, para o ganho de peso das fêmeas, foram estimadas em 0,208 e $0,187 \%$, respectivamente, em função da menor soma de quadrados dos desvios (Tabela 4, Figuras 2 e 3). Os machos apresentaram maior exigência em triptofano que as fêmeas. Entretanto, HUNGHAR e THOMAS (1976) observaram somente mínimas diferenças nas exigências de triptofano para machos e fêmeas, sendo que os machos necessitam, em média, de $0,0043 \%$ a mais de triptofano que as fêmeas.

Os resultados de exigência para as fêmeas, obtidos por meio de análise LRP, uma vez respeitada a interpretação biológica, subestimaram o nível ótimo de triptofano (Trp) para o máximo desempenho das aves. Portanto, com base nos parâmetros observados, respeitando-se o ajuste estatístico, obtido por meio de regressão quadrática, pode-se sugerir exigência mínima de triptofano total para frangos de corte machos e fêmeas, de 1 a 21 dias de idade, de 0,212 e 0,208\% ou de 0,069 e $0,067 \%$ de Trp/Mcal de EM, respectivamente. Resultados superiores foram verificados por FREEMAN (1979), que obteve exigência de triptofano de 0,24 e $0,22 \%$ para pintos de corte, machos e fêmeas, de 0 a 7 dias de idade.
As estimativas de exigência em triptofano obtidas neste estudo foram superiores àquelas citadas por HEWITT e LEWIS (1972), WOODHAM e DEANS (1975), CAREW et al. (1983) e pelo NRC (1994); semelhantes às obtidas por BEHM et al. (1991); e inferiores àquelas citadas por DEAN e SCOTT (1965), AEC (1987), ABEBE e MORRIS (1990), ROSTAGNO et al. (1992), AEC (1993) e PARR e SUMMERS (1991).

Segundo WILLIAMS (1995), a avaliação precisa da exigência de aminoácidos das aves para mantença e crescimento e a suplementação exata são essenciais para otimização do crescimento e da produção. As vantagens de se utilizarem os valores de aminoácidos digestíveis, entre outras, é a menor excreção de nitrogênio para o meio ambiente, evitando assim a poluição de nitrogênio.

Portanto, considerando-se o coeficiente de digestibilidade verdadeira do triptofano da dieta basal $(90,33 \%)$ e o valor estimado de exigência de triptofano total, foi calculada a exigência de triptofano digestível em 0,191 e $0,188 \%$ para machos e fêmeas, respectivamente. Estes resultados são inferiores aos de WALDROUP (1996), que recomendaram $0,20 \%$ de triptofano digestível, e superiores àqueles citados nas Tabelas do AEC (1993), que recomendam 0,19\% de triptofano digestível, para as fêmeas. Também são inferiores aos de HAN et al. (1991), os quais verificaram que a exigência por triptofano digestível para frangos de corte no período de 8 a 22 dias de idade foi de $0,20 \%$.

\section{Conclusões}

As exigências nutricionais em triptofano total para frangos de corte, machos e fêmeas, no período de 1 a 21 dias, foram estimadas em 0,212 e $0,208 \%$ ou 0,069 e $0,067 \%$ de Trp/Mcal de EM, respectivamente. As exigências nutricionais em triptofano digestível para frangos de corte, machos e fêmeas, no período de 1 a 21 dias, foram estimadas em 0,191 e $0,188 \%$ ou 0,062 e $0,061 \%$ de Trp/Mcal de EM, respectivamente.

\section{Referências Bibliográficas}

ABEBE, S., MORRIS, T.R. 1990. Effects of protein concentration on Responses to dietary tryptophan by chicks. Br. Poult Sci., 31:267-272.

AEC - 1987. Tabelas de Recomendações para a Nutrição Animal. 5.ed. Antony Cedex, 86p.

AEC - 1993. Feed ingredients formulation in digestible amino acids. Rhodimet Nutrition Guide, 2.ed., Rhône Poulenc Animal Nutrition. 55p. 
ALBINO, L.F.T., ROSTAGNO, H.S., SANT'ANNA, R. et al. 1992. Determinação dos valores de aminoácidos metabolizável e proteína digestiva de alimentos para aves. R. Soc. Bras. Zootec., 21(6):1059-1068.

ALSTER, F.A., CAREW, L.B., FOSS, D.C. Effect of tryptophan deficience on growth, plasma T4, T3, and organ weights of growing chicks. Poult. Sci., 59:1577 (Supplement 1).

BAKER, D.H., HAN, Y. 1994. Ideal amino acid profile for chicks during the first three weeks posthatching. Poult. Sci., 73:1441-1447.

BEHM, G., DRESSLER, D., GAUS, G. et al. 1991. Los aminoacidos en la nutrition animal. Frankfurt: Degussa. 52p.

BRAGA, J.M. 1983. Avaliação da fertilidade do solo (Ensaios de Cатpo). Viçosa: UFV/Imprensa Universitária. 101p.

CAREW JR., L.B., ALSTER, F.A., FOSS, D.C. et al. 1983. Effect of a tryptophan deficiency on thyroid gland, growth hormone and testicular functions in chickens. J. Nut., 113(9):1756-1765.

DEAN, W.F., SCOTT, H.M. 1965. The development of an amino acid reference diet for the early growth of chicks. Poult. Sci., 44(3):803-808.

FREEMAN, C.P. 1979. The Tryptophan Requirement of Broiler Chicks. Br. Poult. Sci., 20:27-37.

HAN, Y., SUZUKI, H., BAKER, D.H. 1991. Histidine and tryptophan requirement of growing chicks. Poult. Sci., 70:2148-2153.

HEWITT, D., LEWIS, D. 1972a. The amino acid requirements of the growing chick. 1. Determination of amino acid requirements. Br. Poult. Sci., 13:449-463.

HUNGHAR, J.G., THOMAS, O.P. 1976. The Tryptophan requirement of male and female broilers during the 4-7 week period. Poult. Sci., 55:379-383.

KOELKEBECK, K.W., BAKER, D.H., HAN, Y. et al. 1991. Research note: effect of excess lysine, methionine, threonine, or tryptophan on production performance of laying hens. Poult. Sci., 70:1651-1653.

NATIONAL RESEARCH COUNCIL - NRC - 1994. Nutrients requirements of poultry, 9.ed. Washington, DC.: National Academic Press. 155p.

PARR, J.F., SUMMERS, J.D. 1991. The effect of minimizing amino acid excesses in broiler diets. Poult. Sci., 70:1540-1549.

POWELL, T.S., GEHLE, M.H. 1977. Evaluation of dietary tryptophan levels as a restriction method for broiler breeder Pullets. Poult. Sci., 56:407-414.
PUPA, J.M.R. Rações para frangos de corte formuladas com valores de aminoácidos digestíveis verdadeiros, determinados com galos cecectomizados. Viçosa, MG:UFV, Imprensa Universitária, 1995. 63p. Dissertação (Mestrado em Zootecnia) - Universidade Federal de Viçosa, 1995.

ROGERS, S.R., PESTI, G.M. 1990. The influence of dietary tryptophan on broiler chick growth and lipid metabolism as mediated by dietary protein levels. Poult. Sci., 69(5):746-756.

ROSTAGNO, H.S., SILVA, D.J., COSTA, P.M.A. et al. 1992. Composição de alimentos e exigências nutricionais de aves e suínos (Tabelas brasileiras). Viçosa, MG: Imprensa Universitária, 4.ed. 59p.

SILVA, D.J. 1990. Análise de alimentos (Métodos químicos e biológicos). Viçosa: UFV, Imprensa Universitária. 160p.

TEETER, R.G., BELAY, T., WIERNUSZ, C.J. Poultry nutrition research. In: ANNUAL PFIZER RESEARCH CONFERENCE, 41, 1992, New York. Proceedings...New York: Pfizer, 1993. p.170-274.

UNIVERSIDADE FEDERAL DE VIÇOSA - UFV. 1995. Sistema de análises estatístcas e genética - SAEG, Viçosa, MG: UFV (Software).

WALDROUP, P.W. Nutrient requirements of broilers. In: SIMPÓSIO INTERNACIONAL SOBRE EXIGÊNCIAS NUTRICIONAIS DE AVES E SUÍNOS, 1996, Viçosa, MG. Anais... Viçosa: DZO, 1996. p.55-63.

WARNICK, R.E., ANDERSON, J.O. 1968. Limiting essential amino acids in soybean meal for growing chickens and the effects of heat upon availability of the essential amino acids. Poult. Sci., 47:281-287.

WILLIAMS, P.E.V. 1995. Digestible amino acids for nonruminant animals: theory and recent challenges. Anim. Feed Sci. Tech., 53:173-187.

WOODHAM, A.A., DEANS, P.S. 1975. Amino acid requirements of growing chickens. Br. Poult. Sci., 16:269-287.

Recebido em: 08/02/00

Aceito em:05/05/00 